\title{
Establishing a normative database for the sagittal configuration of the spine using an objective three dimensional measurement tool (the MIDAS System)
}

\author{
JA Bettany-Saltikov* and JG Warren
}

Address: University of Teesside School of Health and Social Care Borough Road Middlesbrough TS1 3BA UK

Email: JA Bettany-Saltikov* - j.b.saltikov@tees.ac.uk

* Corresponding author

from 6th International Conference on Conservative Management of Spinal Deformities Lyon, France. 21-23 May 2009

Published: 14 December 2009

Scoliosis 2009, 4(Suppl 2):O24 doi:I0.II86/I748-7|6|-4-S2-O24

This abstract is available from: http://www.scoliosisjournal.com/content/4/S2/O24

(c) 2009 Saltikov and Warren; licensee BioMed Central Ltd.

\section{Objectives}

The primary objective of this study was to produce a database of normative sagittal values of the spine in young adult subjects, against which the spines of patients with different spinal dysfunctions could be compared.

\section{Background}

Assessment and retraining of posture is a traditionally integral physiotherapeutic intervention in the treatment of back pain, with the benefit of postural correction exercises for the relief of back pain being well documented. This lack of objective measures for assessing posture does not agree with standards set out by governing bodies in the United Kingdom, which stipulate that treatments should be based on objective markers and evidence-based practice. Previous studies with physiotherapists concluded that there was a need for an assessment system to provide objective, accurate results, displayed quantitatively and visually for Evidence Based Practice.

\section{Methods}

One Hundred healthy subjects aged 20-40 years old were recruited. Ethical approval was granted by the Health and Social Care Ethics committee. Instrumentation: A relatively low-cost, portable system, known as the MIDAS system (Middlesbrough Integrated Digital Assessment System) was used with software specifically designed for the assessment of back posture. (Figure 1)

\section{Procedure}

Data collection involved one tester touching the MIDAS stylus tip to each of the marked spinal points in a standardized order and pressing the foot pedal of the MIDAS to store the position on the computer.

\section{Results}

The overall mean thoracic Sagittal value was 49.2 (SD $10.55)$ degrees and the overall mean lumbar value was 44.93(SD 15.57) degrees. The overall sagittal profile of the back demonstrated that overall the left shoulder, scapula and pelvis were rotated forward by a mean of 8.04 $\mathrm{mm}, 5.9 \mathrm{~mm}$ and $0.15 \mathrm{~mm}$ respectively over the right side of the back.

\section{Conclusion}

Our results should provide a normative database for clinicians (physiotherapists, chiropractors, spinal surgeon) who routinely assess back posture. The method we have devised will also provide an evidenced based objective alternative to just "eyeballing" the patient's posture during clinical evaluation. It is hoped that the MIDAS system can be implemented as a means of quantifying posture in physiotherapy departments in the near future. 


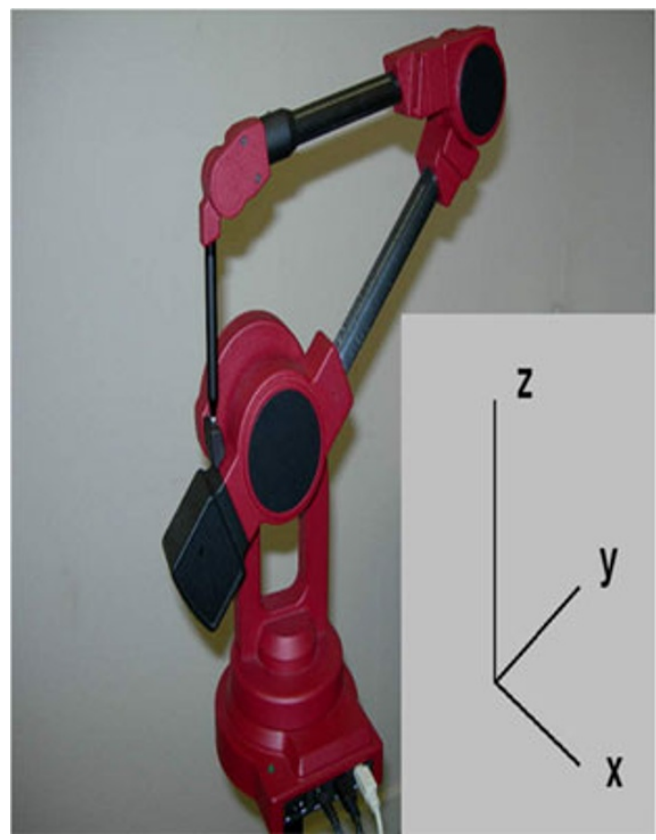

\section{Middlesbrough Integrated Digital Assessment System (MIDAS)}

- low-cost,

- portable system

- software specifically designed for the assessment of back posture in physiotherapy practice

- Very versatile-could be adapted for the assessment of other joints

Figure I

Publish with Biomed Central and every scientist can read your work free of charge

"BioMed Central will be the most significant development for disseminating the results of biomedical research in our lifetime. "

Sir Paul Nurse, Cancer Research UK

Your research papers will be:

- available free of charge to the entire biomedical community

- peer reviewed and published immediately upon acceptance

- cited in PubMed and archived on PubMed Central

- yours - you keep the copyright 